OPEN ACCESS

Edited by:

Alma D. Campos-Parra, National Institute of Cancerology (INCAN), Mexico

Reviewed by: Laila Nayzzel Muñoz-Castellanos, Universidad Autónoma de Chihuahua,

Mexico

Gerardo Leyva-Gómez, National Autonomous University of Mexico, Mexico

${ }^{*}$ Correspondence: Macrina Beatriz Silva-Cázares macrina.silva@uas/p.mx

Specialty section:

This article was submitted to Molecular and Cellular Oncology, a section of the journal

Frontiers in Oncology

Received: 05 February 2021 Accepted: 15 March 2021 Published: 01 April 2021

Citation:

Saavedra-Leos MZ, Jordan-Alejandre E, López-Camarillo C, Pozos-Guillen A,

Leyva-Porras $C$ and Silva-Cázares MB (2021) Nanomaterial Complexes Enriched With Natural Compounds

Used in Cancer Therapies: A Perspective for Clinical Application.

Front. Oncol. 11:664380.

doi: 10.3389/fonc.2021.664380

\section{Nanomaterial Complexes Enriched With Natural Compounds Used in Cancer Therapies: A Perspective for Clinical Application}

\author{
María Zenaida Saavedra-Leos ${ }^{1}$, Euclides Jordan-Alejandre ${ }^{2}$, César López-Camarillo ${ }^{2}$ \\ Amaury Pozos-Guillen ${ }^{3}$, César Leyva-Porras ${ }^{4}$ and Macrina Beatriz Silva-Cázares ${ }^{1 *}$ \\ ${ }^{1}$ Coordinación Académica Región Altiplano, Universidad Autónoma de San Luis Potosí, Matehuala, Mexico, 2 Posgrado en \\ Ciencias Genómicas, Universidad Autónoma de la Ciudad de México, Mexico City, Mexico, ${ }^{3}$ Laboratorio de Ciencias \\ Básicas, Facultad de Estomatología, Universidad Autónoma de San Luis Potosí, San Luis Potosi, Mexico, ${ }^{4}$ Laboratorio \\ Nacional de Nanotecnología, Centro de Investigación en Materiales Avanzados S.C. (CIMAV), Chihuahua, Mexico
}

Resveratrol and quercetin are natural compounds contained in many foods and beverages. Reports indicate implications for the health of the general population; on the other hand the use of both compounds has interesting results for the treatment of many diseases as cardiovascular affections, diabetes, Alzheimer's disease, viral and bacterial infections among others. Based on their capacities described as anti-inflammatory, antioxidant, and anti-aging, resveratrol and quercetin showed antiproliferative and anticancer activity specifically in maligned cells. These molecular characteristics trigger the pharmacological repurposing of both compounds and improved its research for treating different cancer types with interesting results at in vitro, in vivo, and clinical trial studies. Meanwhile, the development of different systems of drug release in specific sites as nanomaterials and specifically the nanoparticles, potentiates the personal treatment perspective in conjunct with the actual cancer therapies; regularly invasive and aggressive, the perspective of nanomedicine as higher effective and lower invasive has gained popularity. Knowledge of molecular interactions of resveratrol and quercetin in diseases confirms the evidence of multiple benefits, while the multiple analyses suggested a positive response for the treatment and diagnostics of cancer in different stages, including at metastatic stage. The present work reviews the reports related to the impact of resveratrol and quercetin in cancer treatment and its effects when the antioxidants are encapsulated in different nanoparticle systems, which improve the prospects of cancer treatment.

Keywords: nanomaterials, cancer, quercetin, resveratrol, pharmacological repurposing 


\section{INTRODUCTION}

Cancer is a compound collective of multi-factorial diseases brought about by intracellular environmental both for aspects such genetic, epigenetic, metabolic deregulations, and other risk-factors $(1,2)$. This complex of diseases arises from many variations at the molecular level that produce deregulations in molecular pathways, intermediary molecules, and losing control in distinct pathways, stimulating tumorigenesis, associating it with lifestyle, longevity, and other risk factors related to contemporary life. However, palaeontological evidence revealed cancer in fossil remains up to 1.98 million years $(3,4)$. Nowadays, cancer has grown into the public health problem of universal attention because the treatments' high cost and its invasiveness have generated several types of research on different drugs and modern treatments, fewer invasive and more efficient $(5,6)$. The progress of technologies such as nanomedicine $(\mathrm{Nm})$ has opened new scopes for the treatment of many diseases (7). By definition, Nm serves to improve the biodistribution and in situ drug release to deal with a specific disease, specifically in pathologies whose strategies are invasive and nonspecific. For example, it could improve the release of chemotherapeutic drugs in the therapy of cancer and could increase the balance between the effectiveness and toxicity of the drugs (8). In this context, the application of different nanomaterials in the form of nanoparticles (Nps) has attracted attention because of the multiple advantages that are presented, such as low manufacturing cost, the delivery of drugs to specific sites, less invasive therapies, and greater efficiency in the treatment and recovery (9). Nowadays, cancer treatment comprises the application of drugs and chemotherapy, along with surgical intervention (10). For cancer therapy, alternative drugs as resveratrol $(\mathrm{Rv})$ and quercetin $(\mathrm{Qr})$ have shown potential results in their treatment, since their chemical characteristics allow them complexing with different Nps increasing their release $(11,12)$

(Figure 1 and Table 1).

The present work reviews the perspectives and advances in implementing these drugs and its complexing with nanomaterials for their use in cancer treatment.

\section{CURRENT DRUGS IMPLICATED IN CANCER TREATMENT}

Nowadays, the application of chemotherapeutic drugs is a conventional treatment perspective, where each treatment must be specific for the type of cancer $(19,20)$. Constant research on

TABLE 1 | Examples of chemical interaction between Rv and Qr with different nanoparticles.

\begin{tabular}{llc}
\hline Nanomaterial example & Chemical interaction & ref \\
\hline PEG & $\mathrm{R} v-\mathrm{OH}-\mathrm{OH}-\mathrm{PEG}$ & $(13)$ \\
Chitosan nanoparticle & $\mathrm{Rv}-\mathrm{O}-\mathrm{H}-\mathrm{NH}_{2}-\mathrm{chitosan}$ & $(14)$ \\
Graphene Oxide (GO) & $\mathrm{GO}=\mathrm{O}-\mathrm{HO}-\mathrm{Rv}$ & $(15)$ \\
Silver nanoparticle & $\mathrm{Qr}=\mathrm{O}-\mathrm{Ag}-\mathrm{O}=\mathrm{Qr}$ & $(16)$ \\
Iron oxide nanoparticles & $\mathrm{Qr}-\mathrm{HO}-\mathrm{H}-\mathrm{Gly}$ & $(17)$ \\
Graphitic carbon nitride nanoparticles & $\mathrm{Qr}-\mathrm{HO}-\mathrm{H}-\mathrm{NH}-$ &
\end{tabular}

A

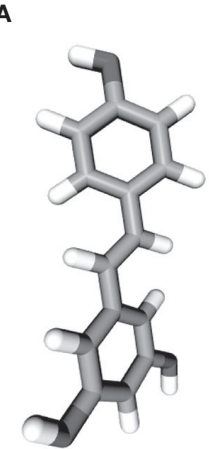

B

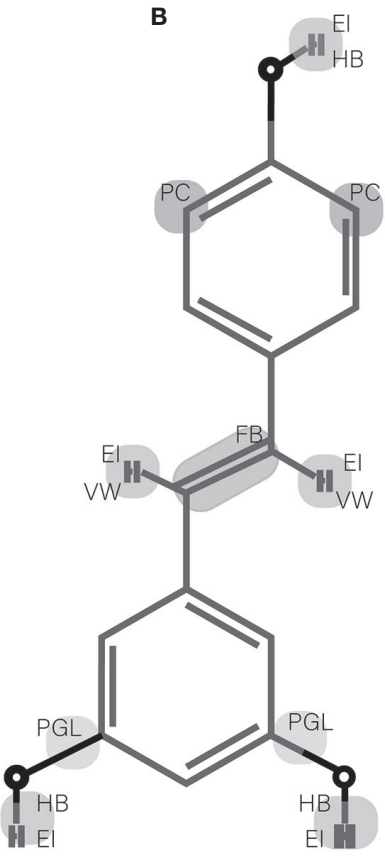

C

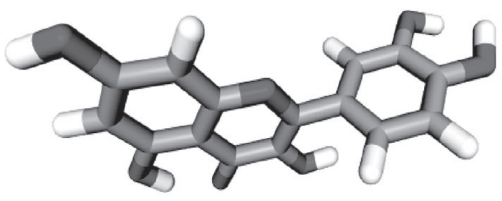
f

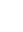


new drugs and new prospects has brought about novel points of view with respect to the current cancer therapy (21). For example, Zhou et al. conducted a clinical phase 3 trial in which they tested the response of lung cancer (LC) patients to Atezolizumab (Az) plus chemotherapy, showing that this combination led to patients having more prolonged survival and shorter survival likelihood of relapse (22). In another study, the effect of Lutetium-177-Dotatate, an experimental drug in phase 3 for the therapy of neuroendocrine tumors, showed that the participants treated with Lutetium-177-Dotatate showed further survival rate; besides, the participants showed a higher progression-free survival (PFS) in comparison with the control group treated with high doses of Octreotide LAR (20 to $30 \mathrm{mg}$ ) (23). The Olaparib impact in subjects with human epidermal growth factor receptor type 2 (HER2) negative breast cancer (BC) diagnosis showed important benefits, and the data suggested that the application of Olaparib leads to PFS for a more extended period of 2.8 months, while the risk of disease progression was $42 \%$ lower compared to monitored control groups (24). The same research group showed the PFS in BC patients treated with Olaparib compared to chemotherapy treatment, showing well toleration at the secondary effects at the studied population. Besides, they proved that Olaparib treatment didn't show cumulative toxicity on prolonged treatment (25). Recently in 2020, Sternberg et al. demonstrated that Enzualtamide in combination with androgen deprivation for therapy of castration-resistant prostate cancer (PC) improved the mean survival and showed that the probability of death in the experimental group was $27 \%$ lower compared to the control group (26). In a prospective study conducted in 679 patients, Cremonili et al. determined that the effectiveness of FOLFOXIRI-Bevacizumab in the therapy of colorectal cancer (CRC) turns out to be better efficient in the treatment of cancer compared to patients treated with chemotherapy (27). Li et al. used Helicobacter pylori plus vitamin and garlic supplements to treat gastric cancer (GC); statistical data showed the reduction of the risk of death from GC and a lower incidence of GC (28). Other approaches have focused on the treatment with naturally occurring compounds; for example Stancioiu et al. showed the efficiency of spirulina, curcumin $(\mathrm{Cm})$, and Boswellia in the treatment of thyroid nodules; the placebo-controlled study counted 34 patients treated during three months showing that the use of natural compounds reduced the nodule size (29). Many researchers demonstrated the efficiency of Rv and Qr use for multiple diseases' treatment. Gal et al. showed that improving red blood cell aggregation using $\mathrm{Rv}$ in conjunct with exercise improved the hemorheological properties (30). In Alzheimer's disease with Rv modulation of neuro-inflammation, they showed the regulation of genes related to neurodegenerative disorders as sirtuin 1 (31). Glycemic and HDL-cholesterol levels could be controlled by $\mathrm{Rv}$ regulating genes as PPAR- $\gamma$ and sirtuin 1 in patients with type 2 diabetes mellitus and coronary heart disease improving the metabolic status of patients after 4-weeks of treatment, notwithstanding the study has some limitations but suggested a relevant effect of $\mathrm{Rv}$ in type 2 diabetes mellitus patients (32). Most et al. demonstrated the Rv impact in fat oxidation mediated by the 12 -week treatment with $\mathrm{Rv}$; the results suggested the modification in the microbiota of patients, specifically in men; this data suggested a positive effect in fat oxidation and mitochondrial oxidative capacity. Nevertheless more studies are necessary for understanding the correlation between gender and therapy effect (33). Another study analyzed 85 patients with stable coronary heart disease. The study reported improvement of the treatment with $\beta$-blockers, statins, aspirin administrated with $\mathrm{Qr}$ as adjuvant, proving the cardioprotective properties of Qr at different levels (34). On the other hand, the use of Qr for treating different pathogens was analyzed in the recurrence of HPV. 59 patients were treated for 551 days, proving that the treatment showed $100 \%$ patients were HPV free. The analysis of results did not show adverse experiences in symptomatic patients; in contrast, the results weren't replicable in asthma patients; for these reasons more studies are necessary (35). Another Qr application is the control of metabolic diseases. The Qr supplementation limited Citrobacter rodentium colitis effects, consistent with other studies that have shown an impact in the modification of microbiota and in the inflammatory process. Nevertheless, Citrobacter rodentium is a non-human pathogen, but the data suggested the possible Qr use for glut pathogen treatment (36). Likewise, Qr treatment improved the morphology and histopathology in testis. The treatment increased plasma and testicular testosterone concentrations, suggesting that $\mathrm{Qr}$ could prevent the toxic effects induced by sodium arsenite (37). Notwithstanding, pharmacological reuse of $\mathrm{Rv}$ and $\mathrm{Qr}$ for cancer treatment has increased since researchers have shown, among other effects, their anti-inflammatory, antioxidant, and anticancer effects.

\section{Perspectives of Resveratrol in Cancer Treatment}

Using Rv as drug in cancer treatment has been studied. Rv is a natural polyphenolic stilbene produced by certain plants with antioxidant, anticancer, anti-inflammatory, and anti-aging properties (38-41). The $\mathrm{Rv}$ investigation for cancer treatment confirmed these properties in different pathologies like rheumatoid arthritis, Alzheimer's disease, type 2 diabetes, allergic rhinitis, and cancer $(31,42-44)$. Researchers have studied the uses of $\mathrm{Rv}$ for cancer therapy. Banaszewska et al. reported Rv's impact on the reduction of the ovarian and adrenal androgens in the treatment of polycystic ovary syndrome (POS) (45). Another clinical trial published showed Rv's effect on reducing Vascular Endothelial Growth Factor (VEGF) and Hypoxia-Inducible Factor 1-alpha (HIF1) expression in granulose cells in women with POS. The study showed a relation between the protective effect of $\mathrm{Rv}$ in the patients and changes in sexual hormone levels probably by the angiogenesis pathway modification related to the VEGF and HIF1 expression levels; besides, the study suggested that the Rv consumption leads to a high-quality of the oocyte and embryo rate (46). The analysis of phytotherapeutic approach in preventing PC relapse by applying turmeric, $\mathrm{Rv}$, green tea, and broccoli sprout reported in a pilot study, revealed the use of phytotherapeutics as a 
workable approach to prevent a relapse of PC and as a potential treatment in men with biochemically recurrent PC, and a moderate increase rate in serum prostate-specific antigen (47). $\mathrm{Rv}$ has been examined in $\mathrm{BC}$ treatment in a group of female mice $(\mathrm{C} 57 \mathrm{BL} / 6)$ that received a special diet plus Rv; the treated group developed tumors with a smaller size in contrast with the control group; likewise the $\mathrm{Rv}$ presence in situ indicated a protective bringing about in the BC development (48). Conversely, other reports indicated that $\mathrm{Rv}$ can induce $\mathrm{BC}$ apoptosis via $\mathrm{p} 53$ by the phosphorylation of Ser-15 and that effect can masked by the dihydrotestosterone in these cells by the receptor competition; however, the result also suggested a protective role induced by the induction of apoptosis mediated by Rv (49). Other investigations treated CRC cells with $\mathrm{Rv}$ in conjunct with pharmacological inhibitors. The data exposed that $\mathrm{Rv}$ affects cell phenotype, suppressing invasion, while the viability reduction of cells contrasted to pharmacological inhibitors. Associating the effect with the Sirt1 up-regulation, FAK down-regulation, and with the inhibition of focal adhesion, Rv use showed the NF- $\kappa \beta$ inhibition pathway by suppression of molecule intermediates involved in invasion, metastasis, and apoptosis (50). Another investigation exhibited the anti-tumor effects in the CRC cells of Rv. The authors showed that $\mathrm{Rv}$ application in conjunct with MALAT1 lentivirus short hairpin RNA, inhibited the $\mathrm{Wnt} / \beta$ catenin signal pathway by the interference in the gene expression of targets such as c-Myc, MMP-7, and MALAT1 (51).

\section{Perspectives of Quercetin in Cancer Treatment}

Qr is a naturally occurring flavonoid found in a wide variety of fruits as watermelon, cantaloupe, avocado (contains one Qr unit/ piece), blueberries (96 units), and Apples (24-58 units), vegetables as tofu, squash, and corn (one unit), yellow onions (326 units), and green beans with (25 units), beverages as tea, Lipton (26 units), and wine containing (8.4 units) (52). Qr is investigated for its biological activity as antioxidant, anti-inflammatory, and anticancer molecule. Besides, the antiproliferative and proapoptotic $\mathrm{Qr}$ activity is unique in cancer cells (53-55). In vitro research reported the improvement of apoptosis induction in human melanoma cells treated with $\mathrm{Qr}$ in comparison with tamoxifen (Tx). The use of $3 \mu \mathrm{M}$ of each component triggers an important change in the clonogenic capacity of M10, M14, and MNT1 cell lines, likewise the ability of $\mathrm{Qr}$ to promote cell apoptosis by the heat shock protein-70 (Hsp70) downregulation. The data suggested $\mathrm{Qr}$ and $\mathrm{Tx}$ protective role in melanoma, indicating the potential effect of both drugs in cancer treatment (56). Nowadays, many strategies result in dosedependent toxicity as doxorubicin (Dx), being a common hazard to continuing therapy, specifically in drug-resistant cancers. In liver cancer ( $\mathrm{LiC})$, the protective role of $\mathrm{Qr}$ in treating toxicity in mice models revealed that Qr potentiated the anti-tumor effect of Dx dose-dependent toxicity and protected normal cells from the toxicity generated by toxic therapy. The accumulation of p53 mediated the Qr anti-tumor effect in LC cells, likewise the subsequent activation of mitochondrial apoptosis by the cleavage pro-caspases. The Qr use for toxicity treatments could protect the normal cells of the patient and could improve therapy resistance (57). Recently the Qr effectiveness as an adjuvant in the therapy of advanced pancreatic cancer (PcC) and other cancers types was demonstrated. Gemcitabine (Gc) use in $\mathrm{PcC}$ is frequent, but normally drug resistance development is the source of chemotherapy failure. The therapy, enriched with $\mathrm{Qr}$ induced apoptosis, causes the cell arrest in the $S$ phase and increases the p53 expression; besides, the boosted Gc effect by Qr, especially in cancer cells resistant to Gc, was observed (58). Furthermore, the evidence indicated Qr's anticancer role in $\mathrm{PcC}$ resistance to $\mathrm{Gc}$ treatment, presenting a relation between the high mortality rate and the receptor for advanced glycation end products and its role in different signaling cascades. They tested autophagy stimulation in $\mathrm{PcC}$ cell lines resistant to $\mathrm{Gc}$ treated with $\mathrm{Qr}$ as an adjuvant. The results implied the mediation of the autophagy effect by the deletion of advanced glycation end products which conduced to the increase in the ratio of $\mathrm{Bax} / \mathrm{Bcl}-2$ and the down-regulation in NF- $\kappa \beta$ p 65 expression, unleashing the CASP3 dependent apoptosis in the cell lines studied (59). Other reports indicated the absence or low Qr toxicity in treated rats with PC. The data showed that a dose of 30-3,000 $\mathrm{mg}$ of Qr/ $\mathrm{kg}$ during 28 days did not show secondary effects at the experimental groups, demonstrating that $\mathrm{Qr}$ can generate chemo-protection in vivo models by down-regulation in oncogenes related to cell survival and a regulation in proteins related with apoptosis signaling (60). Furthermore, Qr could be employed as a preventive therapy in BC in female ACI rats by providing an enriched food with a dose of $2.5 \mathrm{~g} / \mathrm{kg}$ of Qr for eight months. The rats fed with Qr and estrogen $17 \beta$-estradiol showed a higher PFS rate in comparison with the rats powered only with estrogen $17 \beta$-estradiol. The survival rate in the fed group of $\mathrm{Qr}$ plus estrogen $17 \beta$-estradiol was lower compared with the group powered only with $\mathrm{Qr}$ (61). A clinical trial, focusing on the gene expression of resistin in women with weight problems and POS, tested the Qr impact at metabolic and hormonal levels. A daily consumption of 1,000 mg of Qr during 12 -weeks can down-regulate the resistin gene, decreasing plasma levels of POS. Qr could modulate the expression of $3 \beta$ hydroxysteroid dehydrogenase, Cytochrome P450 11A1, Cytochrome P450 17A1, 17 $\beta$-hydroxysteroid dehydrogenases, androgen production, among others (62). A phase I and II study showed the safety, tolerability, and dosage determination of muscadine grape processed (known as MPX, comprising $1.2 \mathrm{mg}$ of ellagic acid, $9.2 \mu \mathrm{g}$ of $\mathrm{Qr}$, and $4.4 \mu \mathrm{g}$ of trans-Rv in $500 \mathrm{mg}$ tablet) in recurrent PC cases. 4,000 mg per day was the highest safety dose and the plasma levels were undetectable. The principal secondary effects reported were flatulence, soft stools, abdominal distension and eructation. However, the treatment was tolerated during 19.8 months, while most of the patients did not show relapsed during the treatment (63). Wilms et al. reported genetic polymorphism that affected the ingestion of Qr. During the study, the volunteers ingested $1 \mathrm{~L}$ of blueberry and apple juice per day with a content of $97 \mathrm{mg}$ of Qr per liter for four weeks. Only one of 34 polymorphisms analyzed appeared influenced in $\mathrm{Qr}$ metabolism mediated by the NQO1 gene expression, resulting in better metabolism of Qr. Furthermore, they viewed the $\mathrm{Qr}$ antioxidant role on ex vivo models is highly beneficial in the 
stressed subjects (64). Pharmacokinetics of trans-Rv and Qr were reported in a combinatory dietary. Researches dosed 2,000 mg of trans-Rv and $500 \mathrm{mg}$ of Qr plus a small amount of alcohol (5\% in $100 \mathrm{ml}$ ) during breakfast; this concentration ratio didn't affect the pharmacokinetics of drugs. They showed the toleration of 2,000 mg of dosage by healthy subjects presented diarrhea as principal secondary effect (65).

\section{NANOPARTICLES AND ITS USE IN CANCER TREATMENT}

In past years the $\mathrm{Nm}$ experimented an exponential growth, generating new approaches in the treatment of several diseases including different types of cancer (66). The progress generated by the research has generated remarkable progress in synthesis, fabrication, and characterisation of Nps specifically as liposomes for intravenous administration $(67,68)$. Nps can form complex with polymers, metals, and inorganic materials for controlling the delivery efficiency and effective properties. NP synthesis with indocyanine green core, coated with poly (lactic-co-glycolic acid) and cancer cell membrane has impacted the in vitro and in vivo models; the treated groups with the system plus laser triggered cell lysis. The therapy inhibited tumor growth 6 days after starting the treatment. and the survival rate was of $40 \%$; likewise it showed a higher biomimetic rate and the ability of the system in theranostic (69). Perspectives in the BC treatment analyzed the activity of nano carried lipids with supphoraphane and Tx, considered as the "gold line". In some BC treatment molecular subtypes showed that the system potentiated the Tx effect and decreased drug toxicity. This is a regular trouble for quality patients' life and improves the binding affinity of Tx to estrogen receptors (70). A phase 2 clinical trial analyzed the use of nanoparticle albumin (Am)-bound-paclitaxel (Px) in complex with Gemcitabine-Cisplatine (GcCs) in advanced biliary tract cancer therapy. The typical therapy resulted in an average PFS rate of 8 months and overall survival of 11.7 months. Notwithstanding, this approach prolonged the average PFS rate during 14.9 months, and 58\% of participants reported adverse events (71). In another study, Nps of Cm with serratiopeptidase showed that $95 \%$ of the complex could release the drug after $24-\mathrm{h}$ at physiological conditions. Different cytotoxicity rates upper in HeLa cells (IC50 $31.25 \mathrm{mg} / \mathrm{ml}$ ) than MCF7 cells (IC50 $0.7 \mathrm{mg}$ / $\mathrm{ml}$ ) were observed; besides this complex can potentiate the antitumor activity of drugs and induce the apoptosis in different cell lines (72). Different cell lines (LNCaP-AI, PC, MCF-7, BC, and QSG-7701 normal-like) showed a greater response to Dx into Np based on silica enriched with $\mathrm{CaCO}_{3}$. The results showed an accumulative release of Dx into $\mathrm{pH} 7.4$ with $4 \mu \mathrm{g} / \mathrm{ml}$, sufficiently to induced apoptosis in $31.52 \%$ of cells. The effect of the system at in vivo models had tumor growth and progression rate lower. The tumor weight reduction was $71 \%$ in comparison with control groups (73). Photo-thermal therapy was based in a system of polypyrrole with camptothecin-conjugated hyaluronic acid (HA) shell. The Np therapy plus chemotherapy and immunotherapy induced cell death in $4 \mathrm{~T} 1$ cells, while the therapy in female Balb/c mice models showed the detection in situ 4-h post-treatment; besides, increased of CD8+ T cells, CD3 $+\mathrm{T}$ cells, the tumor necrosis factor $\alpha$, interferon- $\gamma$, interleukin- $1 \beta,-2,-4,-6$, and -10 (74). A transformable size/charge Np type-Trojan-Horse, integrating $\mathrm{Dx}$ and pheophorbide showed that increasing the temperature after laser irradiation in oral squamous cell carcinoma 3 was sufficient to induce DNA damage by the Reactive Oxygen Species (ROS) generation, and the acid $\mathrm{pH}$ improved drug release. The in vivo models showed nanoparticle accumulation in situ 24-h post-injection (75). A phase I clinical trial with NPs tested in patients with advanced cancer nonresponsive to standard-of-care treatments demonstrated the efficiency of microRNA-34a in complex with liposomal Nps by inducing cell damage after $93 \mathrm{mg} / \mathrm{m}^{2}$ treatment. The half-life of the system was about $35 \mathrm{~h}$ with a tumor reassessment in $75 \%$ of the participants, while $68 \%$ showed a better expression of genes related with the tumor immune response. Notwithstanding, more of $50 \%$ participants experimented different adverse events (76). A prospective phase I/II study tested the impact of four different treatment profiles. Profile A: $150 \mathrm{mg} / \mathrm{m}^{2}$ of Am Np bound Px and $1,000 \mathrm{mg} / \mathrm{m}^{2}$ of Gc. Profile C: $125 \mathrm{mg} / \mathrm{m}^{2}$ of Am Np bound Px and $1,000 \mathrm{mg} / \mathrm{m}^{2}$ of Gc. Profiles B and D were carried out varying the drugs' concentration for three weeks, plus a week off treatment. The results demonstrated a better cycle for each treatment profile. For profile A, the better cycle was 1.5 , for profile $\mathrm{C}$ was 2.5 , while for profiles $\mathrm{B}$ and $\mathrm{D}$ were 1.5 and 3.5, respectively. The less toxic treatments and better-tolerated profiles were $\mathrm{B}$ and $\mathrm{D}$, which in consequence were used in the phase II study. The patients treated with these profiles presented a partial response. $65 \%$ of the patients treated with profile B showed a better disease control rate, while those treated with profile D showed a disease control of $72 \%$. The PFS rate for each profile was 5.4 and 6.6 months, respectively (77). Another phase II clinical trial performed in metastatic castrationresistant PC patients, consisted in docetaxel (Dc) into Np with functionalized surface for targeting prostate-specific membrane antigen. Results showed a decrease of $50 \%$ in prostate specific antigen rate compared with the baseline. On the other hand, only $14.2 \%$ of patients responded to treatment, $11.9 \%$ patients had a partial response, and $21.4 \%$ patients had stable disease. The PFS rate was 9.9 months (78). On the other hand, Am-bound-Px Np plus $\mathrm{Az}$ in the treatment of $\mathrm{BC}$ patients without prior treatment with $\mathrm{Az}$ during 12.9 months triggered the improvement of PFS during 7.2 months in the treated group. Furthermore $7.1 \%$ of patients presented a complete response to treatment, and $5 \%$ of participants presented adverse effects, showing a high $\mathrm{Np}$ safety rate (79). Another report studied the impact of epirubicin $\left(90 \mathrm{mg} / \mathrm{m}^{2}\right)$, cyclophosphamide $\left(600 \mathrm{mg} / \mathrm{m}^{2}\right)$, and nanoparticle Am-bound-Px $\left(125 \mathrm{mg} / \mathrm{m}^{2}\right)$ in BC patients, with HER2 positive, hormone receptor positives $(\mathrm{HR}+)$ or $\mathrm{TN}$ diagnostic; $47.5 \%$ of patients treated conserved the breast; besides, $72.5 \%$ of the participants concluded the therapy with common adverse event in 55\% patients, showing a higher response and better prognosis; likewise the genomic analyses showed a relation between genetic signatures and the therapy response (80). In a contradictory way, the survival rate in patients with hepatocellular carcinoma (HCC) in a phase 3 study randomized in three different groups: $30 \mathrm{mg} / \mathrm{m}^{2}$ 
group (treated with $30 \mathrm{mg} / \mathrm{m}^{2}$ Dx-loaded Nps), $20 \mathrm{mg} / \mathrm{m}^{2}$ group (treated with $20 \mathrm{mg} / \mathrm{m}^{2}$ Dx-loaded Nps), and control group (standard care), showed that the median survival have no statistical differences. suggesting that the therapy with Dx-loaded Nps was not effective in the control of HCC (81).

\section{Resveratrol Nanoparticles in Cancer Treatment}

Using Nps is useful in biological applications, especially in the implementation of certain natural compounds such as $\mathrm{Rv}$, Table 2.

Table 2 summarizes some examples reported about the using of Rv Nps in the treatment of different cancer types. In 2018, Peñalva et al. determined the increment of bioavailability of $\mathrm{Rv}$ complex with casein Nps. The report described the release of Rv into physiologic $\mathrm{pH}$ and showed that the $100 \%$ of release efficiency happened at gastric fluid $\mathrm{pH}$ after 9-h; besides, the data were similar in Wistar rat models; pharmacokinetics data reported the half-life of about to 2.7-h, i.e., ten times higher accumulation contrasted to another distribution procedure; also, they demonstrated that the excretion of the system was 48-h post-oral administration (87). A study showed that the distribution of Rv into mesoporous silica Nps in PC has 100\% of distribution into $\mathrm{pH} 7.4,8$-h post-administration; the therapy diminished PC3 cells that proliferate with $20 \mu \mathrm{M}$, notwithstanding the IC50 was $14.86 \mu \mathrm{M}$; besides, the use of this system plus Dc showed an increase of $50 \%$ in the cytotoxicity in immune cells to Dc (88). In another 2018 study, the Rv used as adjuvant to omega-3 polyunsaturated fatty acids encapsulated in a lipid matrix showed $25 \%$ minor oxidation rate in rat models; the complex integration in the HT-29 CRC cells was $277 \%$ greater, and the cell growth inhibition-rate improved at $72-\mathrm{h}$ post-treatment in different adenocarcinoma cells lines; besides, the CASP3 activation in cells was $150 \%$ higher compared with the control groups. The cell proliferation in the treated group was $20.4 \%$ lower in contrast with the controls (82). The brunt of Rvferulic acid was carried on chitosan coated folic acid into solid lipidic-Nps into apoptosis induction; they disclosed the drugrelease was $42.87 \%$; meantime the IC50 was detected around 10 $\mu \mathrm{g} / \mathrm{ml}$; besides the induction of apoptosis was sharper in HT-29 cells and NIH 3T3 cells evaluated with the compound in relation with non-treated groups (89). An in vivo research analyzed the impact of Rv and Dc encapsulated in lipid-polymer hybrid Nps conjugated with epidermal growth factor (EGF); the pharmaceutical co-delivery in vitro was $90 \%$ in HCC827 cells. Contrarily, the results of co-release in HUVEC cells did not show a difference between the treated group and the control group, Furthermore, in vivo models showed the localization in situ 48-h post-application in tumor tissue, leading to smaller tumor and a tumor growth rate of $79 \%$ lower in comparison with the control group (90). In 2016, a study analyzed the impingement of Rvgold Nps complex in MCF-7 (BC cells) in invasive process prompted by 12-O-tetradecanoylphorbol-13-acetate. The therapy with $10 \mu \mathrm{M}$ of the complex inhibited the cellular migration and invasion, seemingly by the block of NF-kB phosphorylation and the successive activation of MMP-9 and COX-2, the molecules required in the metastatic cancer process (91). In Nps of Rv loaded in nano-capsules in melanoma mice model, in vitro results showed that $100 \mu \mathrm{M}$ and $300 \mu \mathrm{M}$ decreased the cell viability of B16F10 cells between 24 and 72$\mathrm{h}$ post-treatment; besides, the studied mice produced tumors smaller, 10 days post-therapy in contrast with the control group (92).The application of Nps into the theranostic procedure has effective impact in the employment of Human neuroglioma with down toxicity $(<10 \%)$; the system supplemented with $\mathrm{Rv}$, showed the induction of apoptosis in $81.4 \%$ of the treated cells; besides, their results showed greater targeting in tumor cells 5 -min posttreatment, and it improved the localization in situ after 6 -h posttreatment (83). On the other hand, $\mathrm{Lv}$ et al. reported the manufacture of a micro-bubble structure capable of discharging $\mathrm{Rv}$ in an exact $\mathrm{pH}$; it was explained that the capability of this system to deliver or release $\mathrm{Rv}$ was faster in acid $\mathrm{pH}(\sim 5.0)$; a lower $\mathrm{pH}$ was more proximal to physiologic condition $(\sim 7.0)$; besides, its bio-safety was higher that others systems (93). In vitro and in vivo experiments analyze the brunt of the encapsulation of $\mathrm{Rv}$ on Am NPs plus human serum albumin (HSA), in PANC-1 cells and Balb/c nude mice. The procedure could encapsulate $62.5 \%$ of $\mathrm{Rv}$ and efficient drug release in $\mathrm{pH} 5.0$ at $37^{\circ} \mathrm{C}$; the system unleashed in most cells the cellular apoptosis ( $85 \%$ ) by pyknotic nuclei formation; also the half-life time of the $\mathrm{Np}$ was improved with $\mathrm{HAS}$ at in vivo models. Furthermore the system didn't have tissue toxicity (84). Another study demonstrated the apoptotic potential of Gc in human ovary cancer using $\mathrm{Rv}$ as a reducing and stabilizing agent in silver NPs; the system was conducted to a rate lower than $60 \%$ in the viability and cellular proliferation in A2780 line; likewise,

TABLE 2 | Examples of different nanoparticles loaded with Resveratrol and their impact in the control of cancer.

\begin{tabular}{|c|c|c|c|c|c|c|}
\hline Model & System & System size & Apoptosis induction by & C.P & T.G. & Ref. \\
\hline $\begin{array}{l}\text { Human colorectal } \\
\text { cancer }\end{array}$ & Lipid matrix & $1000 \pm 1.8 \mathrm{~nm}$ & Casp3 & $79.6 \%$ & $31.4 \%$ & $(82)$ \\
\hline $\begin{array}{l}\text { Human } \\
\text { neuroglioma }\end{array}$ & $\begin{array}{l}\text { Poly(d,l-lactide-co-glycolide) lipid covalently conjugated with } \\
\text { folic acid and indocyanine green }\end{array}$ & $104.5-121.1 \mathrm{~nm}$ & N.R. & $18.6 \%$ & $7.1 \%$ & (83) \\
\hline Pancreatic cancer & Albumin plus human serum albumin & $120 \pm 2.6 \mathrm{~nm}$ & Pyknotic nuclei formation. & $15 \%$ & N.V.T. & (84) \\
\hline $\begin{array}{l}\text { Human Ovary } \\
\text { cancer }\end{array}$ & Gemcitabine-silver & $20 \mathrm{~nm}$ & $\begin{array}{l}\text { Free radical generation, DNA damage } \\
\text { and CASP3 and CASP9. }\end{array}$ & $40 \%$ & $20 \%$ & (85) \\
\hline $\begin{array}{l}\text { Breast cancer } \\
\text { (Triple-negative) }\end{array}$ & Oxidized mesoporous carbon & $240.1 \mathrm{~nm}$ & PAPR cleavage and activation of CASP3. & $50 \%$ & N.R & (86) \\
\hline
\end{tabular}

C.P., Cell Proliferation; T.G., Tumor Growth; N.R., Non-Reported; N.V.T, Non-Visible Tumor. 
it showed the free radical generation, and the treated cells raised the CASP3 and CASP9 expression. Furthermore the system conduced to DNA damage and the consecutive apoptosis induction (85). On the other hand, Gumireddy et al. generated a novel nano-compound based on 2-Hydroxypropyl $\beta$ cyclodextrin in complex with $\mathrm{Cm}$ and $\mathrm{Rv}$ in a solid lipid NP; this formulation increased the solubility of the NP. They confirmed that the bio-availability and the anticancer activity of the compounds had risen; in vitro application argued that drugs released were optimal in the physiological condition with an IC50 of $9.9 \mu \mathrm{M}$ (94). The Rv effect in MDA-MB-231 BC cells promoted by the oxidized mesoporous carbon-Nps raised the intracellular levels of Rv in BC cells; the results pointed a 2.8 foldchange higher in relation with the control group; the apoptosis induction was $40 \%$ sharper in the control group; also they showed the compound caused apoptosis by the PAPR cleavage and activation of CASP3. Also the cytotoxicity of the Np was lower 24-h post-treatment (86). Another perspective demonstrated in primary patient samples of chronic lymphocyte leukemia the improved transfection of ribonucleic acids, such as mRNA and siRNA encapsulated in Nps mediated by $\mathrm{Rv}$; this method proved the improvement of transfection rate after 1-h of exposition with $10 \mu \mathrm{M}$ of $\mathrm{Rv}$, putting that this approach enhances the transfection; besides, the results showed minimum toxicity rate in treated cells (95). For their part, Elgizawy et al. established that the nano-structuration of $\mathrm{Rv}$ inhibits cell proliferation and promoted apoptosis in various human cell lines treated with $12.5 \mu \mathrm{g} / \mathrm{ml}$ of $\mathrm{Rv}$; the protector effect of the system was $33.96 \%$; besides, the anti-tumor activity increased in the Hep-G2, HCT-116, 1301, and in MCF-7 cells 48$h$ post-treatment by the induction of various CASP such as CASP3, CASP6, CASP7 (96).

\section{Quercetin Nanoparticles in Cancer Treatment}

Another attractive natural compound used in cancer therapy analysis is the Qr. Table 3 summarizes some examples reported about the use of Qr Nps in the treatment of different cancer types.

Bishayee et al. studied the Qr gold complex with Nps of poly (DL-lactide-co-glycolide); the treatment of HepG2 HCC, HeLa cells, A375 cells, and WRL-68 cells with the system showed differential noxious factors in cancer cells, especially in HepG2 cells; they proved the arrest in the S phase of the cell cycle, contributing to fewer cell proliferation. The complex has the capacity to interact with DNA and promote the production of ROS conducing the cell apoptosis (102). Other studies in $\mathrm{HaCaT}$ cell line treated with Poly (lactide-co-glycolide) copolymer loaded with $\mathrm{Qr}$ showed that the kinetics at physiological $\mathrm{pH}$ was similar in the acid $\mathrm{pH}$, showing an accumulative drug release of $70 \%$ triggered a lower cancer's cell viability rate in contrast with the control group (103). For its part a second report performed with the same $\mathrm{Np}$ system showed an encapsulation efficiency of $81.7 \%$ and the inhibition of COX-2 after 6-h with UV damage; besides, the capability of $\mathrm{Qr}$ as defensive factor increased in the face of at risk factors (104). Nano-diamonds loaded with Qr in HeLa cells showed that a concentration of 100 $\mu \mathrm{M}$ of Nps inhibited the cell growth in $54 \% 58$-h post-treatment, and the anti-proliferative proprieties appeared in $74 \%$ of the cells; besides, the cell viability reduced to $50 \%, 72$-h posttreatment; the results indicated the induction of apoptosis by the cleavage of pro-form CASP3 72-h post-treatment (105). Other repors revealed that Qr-gold Nps impacted in the autophagy induction and apoptosis in U87 cells, and in male $\mathrm{BALB} / \mathrm{c}$ - mice, the use of $50 \mu \mathrm{g} / \mathrm{ml}$ reduced the cell viability up to $50 \%$; still, in vitro experiments indicated conversion of LC3B-I in LC3B-II. Furthermore the p62 induction was reduced in the Qr treated group; meanwhile, the in vivo results showed a KI-67 decrease; besides, the mice cared for with the system didn't develop detectable tumors, and the treatment could inhibit the PI3K/Akt/mTOR pathway (97). Fifty cervical cancer patient samples treated with NPs of gold loaded with Qr conduced to autophagosome induction and a poorer Janus Kinase 2 expression; besides, the treatment arrested at cells in phase G0/ $\mathrm{G} 1$ and reduced the induction of $\mathrm{S}$ phase; this effect induced the down-regulation of STAT5 and Bcl-2 and upregulation of BAX, BAD, Cyto-c, Apaf-1 and CASP3. Furthermore, the results showed the suppression of the PI3K/AKT pathway, and the cyclin-D1 suppression led to the formation of auto-phagosomes and cell apoptosis (106). Other strategies based on superparamagnetic Nps for cancer therapy enriched with Qr showed in the MDA-MB-231line and HeLa cells line that the system could load $12.1 \%$ of the drug and the encapsulated percentage was up to $80 \%$ of Qr; in physiologic conditions it showed that up

TABLE 3 | Examples of different nanoparticles loaded with Quercetin and their impact in the control of cancer.

\begin{tabular}{|c|c|c|c|c|c|c|}
\hline Model & System & System size & Apoptosis induced by & C.P & T.G. & Ref. \\
\hline Human neuroglioma & Gold nanoparticle & $106.7 \mathrm{~nm}$ & $\begin{array}{l}\text { Autophagosome formation and AKT/ERK } \\
\text { Caspase-3 pathway. }\end{array}$ & $20 \%$ & N.V.T. & $(97)$ \\
\hline $\begin{array}{l}\text { Breast cancer } \\
\text { (Triple-negative) }\end{array}$ & Gold nanoparticles & $4.5 \mathrm{~nm}$ & $\begin{array}{l}\text { Nuclei Fragmentation, Bax and } \mathrm{Bcl}-2 \text { regulation } \\
\text { and suppression of } \mathrm{PI} 3 \mathrm{~K} \text {. }\end{array}$ & $48 \%$ & N.R. & (98) \\
\hline Lung cancer & $\begin{array}{l}\text { Bismuth selenide camouflaged in macrophage } \\
\text { membrane }\end{array}$ & $155.3 \mathrm{~nm}$ & $\begin{array}{l}\text { Down-regulation of HSP70, inhibition of AKT, } \\
\text { induction of CASP } 3 \text { and the downregulation of } \\
\text { metalloproteinase- } 9\end{array}$ & $56.7 \%$ & $17 \%$ & (99) \\
\hline $\begin{array}{l}\text { Human colorectal } \\
\text { cancer }\end{array}$ & $\begin{array}{l}\text { 1,2-distearoyl-sn-glycero-3- } \\
\text { phosphoethanolamine- } \mathrm{N} \text {-methoxy-poly plus } \mathrm{D} \text { - } \alpha \text { - } \\
\text { tocopherol polyethylene glycol succinate }\end{array}$ & $20 \pm 0.6 \mathrm{~nm}$ & $\begin{array}{l}\text { Inhibition of inflammatory molecules, increased } \\
\text { of T-cell activity, and autophagy by the inhibition } \\
\text { of mTOR and Bcl-2. }\end{array}$ & N.R & $16.6 \%$ & (100) \\
\hline Liver cancer & Chitosan-based in nano-hydrogel & $912 \mathrm{~nm}$ & $\begin{array}{l}\text { Increase of the DNA methylation and regulation } \\
\text { of DNMTs. }\end{array}$ & $20 \%$ & N.R & (101) \\
\hline
\end{tabular}

C.P., Cell Proliferation; T.G., Tumor Growth; N.R., Non-Reported; N.V.T, Non-Visible Tumor. 
to $83 \%$ of Qr could be released, 250-h post-treatment, triggering reduction in cell growth. Furthermore the nanocarrier gets an up bio-compatibility and strengthened the Qr intracellular delivery (107). In the context of specific site drug-delivery, Liu et al. reported that polymeric microspheres filled with $\mathrm{Px}$ and $\mathrm{Qr}$ were viable to treat LC; the method showed a $92.6 \%$ of encapsulating efficiency for Px and $90.3 \%$ for Qr; in vitro results showed that the drug-delivery, 2-h post-treatment at physiological condition was $21.87 \%$ for Px and $27.83 \%$ for Qr; besides, in vivo data showed that half-life of Qr in situ was 3.58-h and less than 5\% erythrocytes damaged demonstrated high bio-safety of the compound (108). For their part, Balakrishnan et al. documented the effects of gold Nps loaded with Qr in MCF-7 and MDA-MB231 lines; their results showed 75\% Qr binds in the Np; likewise, $53 \%$ could release at acid $\mathrm{pH}$ and $16 \%$ at physiologic $\mathrm{pH}$, reporting that $50 \mu \mathrm{M}$ induced the reduction of cell viability. They reported the fragmented nuclei and the activation of apoptosis in 52\% of cells, seemingly by the upregulation of Bax and the concomitant down-regulation of Bcl-2. The treated cells showed the slackening of phosphorylation at EGF receptor and the suppression of PI3K/ Akt pathway (98). On the other hand, Ren et al. treated MHCC97H cell lines with Qr gold Nps showing lower cellular migration, the downregulation in $\mathrm{c}-\mathrm{Myc}$, cyclin-D1, CDK1, MMP7 and $\beta$-catenin genes, and the up-regulation of P-27. Furthermore the cleavage of CASP3, CASP9 besides the changes of Cytochrome-c localization increased $20 \%$ the apoptosis rate and regulated AP- $2 \beta /$ hTERT signaling, and $\mathrm{p} 50 / \mathrm{NF}-\kappa \mathrm{B} / \mathrm{COX}-2$ and Akt/ERK1/2 pathway; consistently, mouse models treated showed the tumor volumes and weights were significantly lower (109). Gold nano-cage with tetradecanol was loaded with $\mathrm{Qr}$ and $\mathrm{Dx}$ to analyze the co-delivery in MCF-7/ADR cells determining that the system could release $10 \%$ of Dx and $7 \%$ of Qr after $2-\mathrm{h}$ at $37^{\circ} \mathrm{C}$, showing a relation between the temperature and the release efficiency; besides, the treatment inhibited the expression of permeability glycoprotein in MCF-7/ADR cells; likewise, the rate of early apoptosis was $55.9 \%$, and system arrested $57.9 \%$ cells in G2/M cell cycle phase in treated cells; besides the IC50 of the system was $1.5 \mu \mathrm{g} / \mathrm{ml}$ (110). Zhao et al. camouflaged Qr-loaded hollow bismuth selenide Nps in macrophage membrane for $\mathrm{BC}$ therapy; the system presented rapid binding and drug-releasing, showing a high bio-compatibility in $4 \mathrm{~T} 1$ cells; in vitro data showed the down-regulation of HSP70, 43.3\% apoptosis rate mediated by the AKT phosphorylation inhibition; the induction of cleaved CASP3 and photo-thermal therapy synergy in mouse model proved a strong ability of targeting after 6-h post-intravenous injection and the tumor size reduction presented 8 days posttreatment; interestingly, the metastasis capacity decreased at $17 \%$, and the system presented a low hemolysis rate indicating high biocompatibility (99). Different perspectives of treatment were approached by Nan's research group that produced TPP Chitosan Nps in complex with Qr to treat and prevent skin deterioration and skin cancer in $\mathrm{HaCaT}$ cells and by topical application on mice models; in vitro data revealed that the system increased the internalization and retention in $\mathrm{HaCaT}$ skin cells; in vivo results confirmed the defensive effect of the system after UV damage by the inhibition of NF- $\kappa \mathrm{B} / \mathrm{COX}-2$ signaling pathway by downregulation of $\mathrm{IkB}-\alpha$. In fact, the system prevented the mice from developing edema in the experimental group, showing a higher thickness of epidermis and dermis (111). The therapy with 1,2-distearoyl-sn-glycero-3phosphoethanolamine-N-methoxy-poly (ethylene glycol 2000) and $\mathrm{D}-\alpha$-tocopherol polyethylene glycol succinate in complex with Qr and alantolactone released 7.6\% of total Qr loaded, showing in CT26-FL3 tumor-bearing mice that the treatment had a considerably smaller volume; the therapy reduced the content of Treg cells, showing the inhibition of IL-10, TGF- $\beta$, $\mathrm{IL}-1 \beta$, and CCL2, and the increasing the effect of CD3+ T-cells, and the system improved the survival rate (100). On the other hand, Liu et al. analyze the relation between nanocrystal with different sizes loaded with Qr and its biological effects. The A549 cell treatment with three different concentration systems $(200 \mathrm{~nm}$, $500 \mathrm{~nm}$, and $3 \mu \mathrm{m}$ ) reduced $50 \%$ cellular proliferation, specifically in the $200 \mathrm{~nm}$ and $500 \mathrm{~nm}$ size systems; smaller nanocrystals with higher Qr concentrations correlated with a poorer formation of the microfilaments, blocking the normal localization of the actin fibers, and the reduction of STAT3 expression changes the migration rate after 24-h treatment (112). Other therapy perspectives based on Zr-MOF loaded with Qr could sensitize the DNA in different tumoral cell lines; the treatment triggered an $18 \%$ at the survival rate, and was more sensible to irradiation. The DNA breaking and the induction of $\gamma-\mathrm{H} 2 \mathrm{AX}$ was higher in the treated group; in vivo models showed $8 \%$ of the bio-distribution in situ. The inhibition of HIF1 could suppress the development of neo-vascularization in tumor tissues, and the analysis of BALB/C mice showed that the treated group has a $52.8 \%$ tumor inhibition rate by the downregulation of Ki6 (113). In relation with the effect of Qr on DNA, Abbaszadeh et al. informed that use of chitosanbased in nano-hydrogel loaded with Qr could alter genomic global DNA methylation and down-regulate DNMTs (DNMT1/3A/3B) in HepG2 cancer cells, increasing the level of methylated cytosine, and the correlation between the use of Qr and DNA methylation rate improved the anti-tumor effect (101). Other analyses proved the Qr delivery by $\mathrm{TiO} 2$ and $\mathrm{Al} 2 \mathrm{O} 3 \mathrm{Nps}$ in MCF-7 cells, showing that the use of $25 \mu \mathrm{g} / \mathrm{ml}$ of the system has $90 \%$ bio-compatibility, and the nanocarrier internalized plus irradiation reduced the cell viability at $50 \%$ in relation with the control group, Furthermore the treatment with nano-sheets plus irradiation promoted the ROS production, DNA breaking, and altered the functionalities of mitochondria triggering the apoptosis or other cell death pathways (114). Other processes described for producing economic Nps enriched with HA plus Qr for targeting tumor showed $100 \%$ compound release rate and promoted the internalization by the CD44 receptor in 4T1 cells and HepG2 cells; besides, they showed $26.55 \%$ apoptosis rate, and in vivo data showed that the treatment led to less tumor growth (115).

\section{CONCLUSIONS}

Multiple evidence results of in vitro, in vivo, and of different phases of clinical studies emphasize the perspectives about the potential of natural compounds to apply such as drugs by cancer 
therapy; here we brought to light the general benefits of these compounds in face of synthetic drugs; besides, it showed up the role of the natural particles as an adjuvant in the minimization of the secondary effects in classical therapies as chemotherapy and surgery in diverse studies, and these results showed the improvement in the treated group with natural compounds. In this review, we focused especially on resveratrol and quercetin effects in cancer treatment. We noted an upsurge in interest of investigators to find out the mechanisms of compounds in the cancer treatment, and because of the report of different investigations, the possible specificity of these natural compounds in the sensitization of the abnormal cells that triggered different molecules that conduced to cellular damage by the activation of apoptosis, the induction of this pathway could be related by the activation of other pathways such as caspases, activation of PI3/AKT/mTOR and DNA double-strand break. The development of different techniques boosted the efficiency of the drug release; these technological advances could improve the treatment of cancer by the induction of immune system response; this viewpoint about nanomaterials complexing with different cellular membranes could emphasize the specificity of the drug by cancer cells' treatment. In this understanding, the developer of nanomaterials mediated by in silico applications results in pre-designed system of molecules more efficient for certain types of cancers, potentiating the multiple benefits of nanocomplex; likewise the novel approaches and modification of the classic methodologies could decrease the cost of these nanoparticle production. Despite the promising benefits presented in models in vitro and in vivo about the application of the resveratrol and quercetin complexing with different nano-materials enriched with certain drugs, and because of the insufficient clinical evidence, clinical studies in phase I are currently required to confirm the results referred in models in vitro and in vivo; besides, other technologies could simplify the bridge between these pre-clinical studies and clinical phase I studies, such the 3D culture analysis.

\section{REFERENCES}

1. Tanasova M, Begoyan VV, Weselinski LJ. Targeting Sugar Uptake and Metabolism for Cancer Identification and Therapy: An Overview. Curr Top Med Chem (2018) 18:467-83. doi: 10.2174/1568026618666180523110837

2. Crowley E, Di Nicolantonio F, Loupakis F, Bardelli A. Liquid biopsy: monitoring cancer-genetics in the blood. Nat Rev Clin Oncol (2013) 10:472-84. doi: 10.1038/nrclinonc. 2013.110

3. Chene G, Lamblin G, Le Bail-Carval K, Beaufils E, Chabert P, Gaucherand P, et al. Le(s) cancer(s) de Lucy : une origine préhistorique ? Gynécol Obstét Fertil (2016) 44:690-700. doi: 10.1016/j.gyobfe.2016.10.001

4. Wang J-J, Lei K-F, Han F. Tumor microenvironment: recent advances in various cancer treatments. Eur Rev Med Pharmacol Sci (2018) 22:3855-64. doi: 10.26355/eurrev_201806_15270

5. Siegel RL, Miller KD, Jemal A. Cancer statistics, 2020. CA Cancer J Clin (2020) 70:7-30. doi: 10.3322/caac.21590

6. Dolgin E. Bringing down the cost of cancer treatment. Nature (2018) 555: S26-9. doi: 10.1038/d41586-018-02483-3

7. Liang X-J. Nanotechnology and cancer nanomedicine. Biotechnol Adv (2014) 32:665. doi: 10.1016/j.biotechadv.2014.05.001

8. van der Meel R, Sulheim E, Shi Y, Kiessling F, Mulder WJM, Lammers T. Smart cancer nanomedicine. Nat Nanotechnol (2019) 14:1007-17. doi: 10.1038/s41565-019-0567-y
Novel perspectives to prevent the evolution of any type of cancer are carried out centralized in the natural drugs' treatment. The evidence presented in certain research proposed that a defensive character of resveratrol and quercetin could convert them such as in molecules' potential application in preventive medicine; some data showed the preventive aspect of certain types of diets under a specific plan. The fast advancement in phytopharmaceutical investigation triggered many expansions to reinterpret the treatment for a disease, such as cancer, as complex. The many advantages of natural compounds use have been shown in different cancer types, which frequently have been proven in clinical studies in different phases, which although not concentrated on the resveratrol or quercetin complexing with any type of nano-material, they have showed that the use of these molecules can enhanced because this type of nano-formulations favors not only the treatment, but can be used as preventive complexes and like promising molecules and with hopeful results in the theranostic, thus improving the probabilities of the good progression of the patients.

\section{AUTHOR CONTRIBUTIONS}

MS-L, EJ-A, CL-C, AP-G, CL-P, and MS-C wrote all the sections of the manuscript. The Correspondence author and Principal author conceived and designed the review. All authors contributed to the article and approved the submitted version.

\section{ACKNOWLEDGMENTS}

We would like to thank Mr. Juan Manuel Delgado Cervantes at the Facultad de Medicina de la Universidad Autónoma de San Luis Potosí for the support.

9. Chen Q, Chen J, Yang Z, Xu J, Xu L, Liang C, et al. Nanoparticle-Enhanced Radiotherapy to Trigger Robust Cancer Immunotherapy. Adv Mater (2019) 31:1802228. doi: $10.1002 / \mathrm{adma} .201802228$

10. Audisio RA. The surgical risk of elderly patients with cancer. Surg Oncol (2004) 13:169-73. doi: 10.1016/j.suronc.2004.09.012

11. Tomas-Hernández S, Blanco J, Rojas C, Roca-Martínez J, Ojeda-Montes MJ, Beltrán-Debón R, et al. Resveratrol Potently Counteracts Quercetin StarvationInduced Autophagy and Sensitizes HepG2 Cancer Cells to Apoptosis. Mol Nutr Food Res (2018) 62:1700610. doi: 10.1002/mnfr.201700610

12. Tomko AM, Whynot EG, Ellis LD, Dupré DJ. Anti-Cancer Potential of Cannabinoids, Terpenes, and Flavonoids Present in Cannabis. Cancers (2020) 12:1985. doi: 10.3390/cancers 12071985

13. Wang X, Parvathaneni V, Shukla SK, Kulkarni NS, Muth A, Kunda NK, et al. Inhalable resveratrol-cyclodextrin complex loaded biodegradable nanoparticles for enhanced efficacy against non-small cell lung cancer. Int J Biol Macromol (2020) 164:638-50. doi: 10.1016/j.ijbiomac.2020.07.124

14. Elgizawy HA, Ali AA, Hussein MA. Resveratrol: Isolation, and Its Nanostructured Lipid Carriers, Inhibits Cell Proliferation, Induces Cell Apoptosis in Certain Human Cell Lines Carcinoma and Exerts Protective Effect Against Paraquat-Induced Hepatotoxicity. J Med Food (2021) 24:89100. doi: 10.1089/jmf.2019.0286

15. He X-P, Deng Q, Cai L, Wang C-Z, Zang Y, Li J, et al. Fluorogenic Resveratrol-Confined Graphene Oxide For Economic and Rapid Detection 
Of Alzheimer's Disease. ACS Appl Mater Interfaces (2014) 6:5379-82. doi: 10.1021/am5010909

16. Aziz S B, Hussein G, Brza MA, J. Mohammed S, T. Abdulwahid R, Raza Saeed S, et al. Fabrication of Interconnected Plasmonic Spherical Silver Nanoparticles with Enhanced Localized Surface Plasmon Resonance (LSPR) Peaks Using Quince Leaf Extract Solution. Nanomaterials (2019) 9:1557. doi: 10.3390/nano9111557

17. Amanzadeh E, Esmaeili A, Abadi REN, Kazemipour N, Pahlevanneshan Z, Beheshti S. Quercetin conjugated with superparamagnetic iron oxide nanoparticles improves learning and memory better than free quercetin via interacting with proteins involved in LTP. Sci Rep (2019) 9:6876. doi: 10.1038/s41598-019-43345-w

18. Xu S, Chen L, Ma L. Fluorometric determination of quercetin by using graphitic carbon nitride nanoparticles modified with a molecularly imprinted polymer. Microchim Acta (2018) 185:492. doi: 10.1007/s00604018-3016-y

19. Simon R. Sensitivity, Specificity, PPV, and NPV for Predictive Biomarkers. J Natl Cancer Inst (2015) 107:djv153. doi: 10.1093/jnci/djv153

20. Torres-Román AL, García-Hernández VM, Rangel-López E, Ruiz-García E, Meneses-García A, Santamaría A, et al. Oleamide Induces Cell Death in Glioblastoma RG2 Cells by a Cannabinoid Receptor-Independent Mechanism. Neurotox Res (2020) 38:941-56. doi: 10.1007/s12640-02000280-3

21. Creighton C J. Molecular Classification and Drug Response Prediction in Cancer. Curr Drug Targets (2012) 13:1488-94. doi: 10.2174/138945012803530143

22. Zhou K, Zhou J, Huang J, Zhang N, Bai L, Yang Y, et al. Cost-effectiveness analysis of atezolizumab plus chemotherapy in the first-line treatment of extensive-stage small-cell lung cancer. Lung Cancer (2019) 130:1-4. doi: 10.1016/j.lungcan.2019.01.019

23. Strosberg J, El-Haddad G, Wolin E, Hendifar A, Yao J, Chasen B, et al. Phase 3 Trial of ${ }^{177}$ Lu-Dotatate for Midgut Neuroendocrine Tumors. N Engl J Med (2017) 376:125-35. doi: 10.1056/NEJMoa1607427

24. Robson M, Im S-A, Senkus E, Xu B, Domchek SM, Masuda N, et al. Olaparib for Metastatic Breast Cancer in Patients with a Germline BRCA Mutation. N Engl J Med (2017) 377:523-33. doi: 10.1056/NEJMoa1706450

25. Robson ME, Tung N, Conte P, Im S-A, Senkus E, Xu B, et al. OlympiAD final overall survival and tolerability results: Olaparib versus chemotherapy treatment of physician's choice in patients with a germline BRCA mutation and HER2-negative metastatic breast cancer. Ann Oncol (2019) 30:558-66. doi: 10.1093/annonc/mdz012

26. Sternberg CN, Fizazi K, Saad F, Shore ND, De Giorgi U, Penson DF, et al. Enzalutamide and Survival in Nonmetastatic, Castration-Resistant Prostate Cancer. N Engl J Med (2020) 382:2197-206. doi: 10.1056/NEJMoa2003892

27. Cremolini C, Antoniotti C, Rossini D, Lonardi S, Loupakis F, Pietrantonio F, et al. Upfront FOLFOXIRI plus bevacizumab and reintroduction after progression versus mFOLFOX6 plus bevacizumab followed by FOLFIRI plus bevacizumab in the treatment of patients with metastatic colorectal cancer (TRIBE2): a multicentre, open-label, phase 3, randomised, controlled trial. Lancet Oncol (2020) 21:497-507. doi: 10.1016/S1470-2045(19)30862-9

28. Li W-Q, Zhang J-Y, Ma J-L, Li Z-X, Zhang L, Zhang Y, et al. Effects of Helicobacter pylori treatment and vitamin and garlic supplementation on gastric cancer incidence and mortality: follow-up of a randomized intervention trial. BMJ (2019) 366:15016. doi: 10.1136/bmj.15016

29. Stancioiu F, Mihai D, Papadakis G, Tsatsakis A, Spandidos D, Badiu C. Treatment for benign thyroid nodules with a combination of natural extracts. Mol Med Rep (2019) 20:3:2332-8. doi: 10.3892/mmr.2019.10453

30. Gal R, Praksch D, Kenyeres P, Rabai M, Toth K, Halmosi R, et al. Hemorheological Alterations in Patients with Heart Failure with Reduced Ejection Fraction Treated by Resveratrol. Cardiovasc Ther (2020) 2020:1-8. doi: $10.1155 / 2020 / 7262474$

31. Moussa C, Hebron M, Huang X, Ahn J, Rissman RA, Aisen PS, et al. Resveratrol regulates neuro-inflammation and induces adaptive immunity in Alzheimer's disease. J Neuroinflamm (2017) 14:1. doi: 10.1186/s12974-0160779-0

32. Hoseini A, Namazi G, Farrokhian A, Reiner Ž, Aghadavod E, Bahmani F, et al. The effects of resveratrol on metabolic status in patients with type 2 diabetes mellitus and coronary heart disease. Food Funct (2019) 10:6042-51. doi: 10.1039/C9FO01075K
33. Most J, Penders J, Lucchesi M, Goossens GH, Blaak EE. Gut microbiota composition in relation to the metabolic response to 12 -week combined polyphenol supplementation in overweight men and women. Eur J Clin Nutr (2017) 71:1040-5. doi: 10.1038/ejcn.2017.89

34. Chekalina NI, Shut SV, Trybrat TA, Burmak YH, Petrov YY, Manusha YI, et al. Effect of quercetin on parameters of central hemodynamics and myocardial ischemia in patients with stable coronary heart disease. Wiadomosci Lek Wars Pol 1960 (2017) 70:707-11.

35. Polansky H, Itzkovitz E, Javaherian A. Human papillomavirus (HPV): systemic treatment with Gene-Eden-VIR/Novirin safely and effectively clears virus. Drug Des Devel Ther (2017) 11:575-83. doi: 10.2147/ DDDT.S123340

36. Lin R, Piao M, Song Y. Dietary Quercetin Increases Colonic Microbial Diversity and Attenuates Colitis Severity in Citrobacter rodentium-Infected Mice. Front Microbiol (2019) 10:1092. doi: 10.3389/fmicb.2019.01092

37. Jahan S, Iftikhar N, Ullah H, Rukh G, Hussain I. Alleviative effect of quercetin on rat testis against arsenic: a histological and biochemical study. Syst Biol Reprod Med (2015) 61:89-95. doi: 10.3109/19396368.2014.998350

38. Espinoza JL, Trung LQ, Inaoka PT, Yamada K, An DT, Mizuno S, et al. The Repeated Administration of Resveratrol Has Measurable Effects on Circulating T-Cell Subsets in Humans. Oxid Med Cell Longev (2017) 2017:1-10. doi: $10.1155 / 2017 / 6781872$

39. Evans H, Howe P, Wong R. Effects of Resveratrol on Cognitive Performance, Mood and Cerebrovascular Function in Post-Menopausal Women; A 14Week Randomised Placebo-Controlled Intervention Trial. Nutrients (2017) 9:27. doi: 10.3390/nu9010027

40. Asghari S, Rafraf M, Farzin L, Asghari-Jafarabadi M, Ghavami S-M, Somi M-H. Effects of Pharmacologic Dose of Resveratrol Supplementation on Oxidative/Antioxidative Status Biomarkers in Nonalcoholic Fatty Liver Disease Patients: A Randomized, Double-Blind, Placebo-Controlled Trial. Adv Pharm Bull (2018) 8:307-17. doi: 10.15171/apb.2018.036

41. Hussain S, Marouf B, Ali Z, Ahmmad R. Efficacy and safety of coadministration of resveratrol with meloxicam in patients with knee osteoarthritis: a pilot interventional study. Clin Interv Aging (2018) 13:1621-30. doi: $10.2147 /$ CIA.S172758

42. Khojah HM, Ahmed S, Abdel-Rahman MS, Elhakeim EH. Resveratrol as an effective adjuvant therapy in the management of rheumatoid arthritis: a clinical study. Clin Rheumatol (2018) 37:2035-42. doi: 10.1007/s10067-0184080-8

43. Timmers S, de Ligt M, Phielix E, van de Weijer T, Hansen J, MoonenKornips E, et al. Resveratrol as Add-on Therapy in Subjects With WellControlled Type 2 Diabetes: A Randomized Controlled Trial. Diabetes Care (2016) 39:2211-7. doi: 10.2337/dc16-0499

44. Lv C, Zhang Y, Shen L. Preliminary Clinical Effect Evaluation of Resveratrol in Adults with Allergic Rhinitis. Int Arch Allergy Immunol (2018) 175:231-6. doi: $10.1159 / 000486959$

45. Banaszewska B, Wrotyńska-Barczyńska J, Spaczynski RZ, Pawelczyk L, Duleba AJ. Effects of Resveratrol on Polycystic Ovary Syndrome: A Double-blind, Randomized, Placebo-controlled Trial. J Clin Endocrinol Metab (2016) 101:4322-8. doi: 10.1210/jc.2016-1858

46. Bahramrezaie M, Amidi F, Aleyasin A, Saremi A, Aghahoseini M, Brenjian S, et al. Effects of resveratrol on VEGF \& HIF1 genes expression in granulosa cells in the angiogenesis pathway and laboratory parameters of polycystic ovary syndrome: a triple-blind randomized clinical trial. $J$ Assist Reprod Genet (2019) 36:1701-12. doi: 10.1007/s10815-019-01461-6

47. van Die MD, Williams SG, Emery J, Bone KM, Taylor JMG, Lusk E, et al. A Placebo-Controlled Double-Blinded Randomized Pilot Study of Combination Phytotherapy in Biochemically Recurrent Prostate Cancer: A Pilot Study of Herbal Therapy in Prostate Cancer. Prostate (2017) 77:76575. doi: $10.1002 /$ pros. 23317

48. Rossi EL, Khatib SA, Doerstling SS, Bowers LW, Pruski M, Ford NA, et al. Resveratrol inhibits obesity-associated adipose tissue dysfunction and tumor growth in a mouse model of postmenopausal claudin-low breast cancer. Mol Carcinog (2018) 57:393-407. doi: 10.1002/mc.22763

49. Chin Y-T, Yang S-H, Chang T-C, Changou CA, Lai H-Y, Fu E, et al. Mechanisms of dihydrotestosterone action on resveratrol-induced antiproliferation in breast cancer cells with different ER $\alpha$ status. Oncotarget (2015) 6:35866-79. doi: 10.18632/oncotarget.5482 
50. Buhrmann C, Shayan P, Goel A, Shakibaei M. Resveratrol Regulates Colorectal Cancer Cell Invasion by Modulation of Focal Adhesion Molecules. Nutrients (2017) 9:1073. doi: 10.3390/nu9101073

51. Ji Q, Liu X, Fu X, Zhang L, Sui H, Zhou L, et al. Resveratrol Inhibits Invasion and Metastasis of Colorectal Cancer Cells via MALAT1 Mediated Wnt/B-Catenin Signal Pathway. PloS One (2013) 8:e78700. doi: 10.1371/journal.pone.0078700

52. Sampson L, Rimm E, Hollman PCH, de VRIES JHM, Katan MB. Flavonol and Flavone Intakes in US Health Professionals. J Am Diet Assoc (2002) 102:1414-20. doi: 10.1016/S0002-8223(02)90314-7

53. Gibellini L, Pinti M, Nasi M, Montagna JP, De Biasi S, Roat E, et al. Quercetin and Cancer Chemoprevention. Evid Based Complement Alternat Med (2011) 2011:1-15. doi: 10.1093/ecam/neq053

54. Park MH, Min DS. Quercetin-induced downregulation of phospholipase D1 inhibits proliferation and invasion in U87 glioma cells. Biochem Biophys Res Commun (2011) 412:710-5. doi: 10.1016/j.bbrc.2011.08.037

55. Du G, Lin H, Wang M, Zhang S, Wu X, Lu L, et al. Quercetin greatly improved therapeutic index of doxorubicin against 4T1 breast cancer by its opposing effects on HIF-1 $\alpha$ in tumor and normal cells. Cancer Chemother Pharmacol (2010) 65:277-87. doi: 10.1007/s00280-009-1032-7

56. Piantelli M, Tatone D, Castrilli G, Savini F, Maggiano N, Larocca LM, et al. Quercetin and tamoxifen sensitize human melanoma cells to hyperthermia. Melanoma Res (2001) 11:469-76. doi: 10.1097/00008390-200110000-00005

57. Wang G, Zhang J, Liu L, Sharma S, Dong Q. Quercetin Potentiates Doxorubicin Mediated Antitumor Effects against Liver Cancer through p53/Bcl-xl. PloS One (2012) 7:e51764. doi: 10.1371/journal.pone.0051764

58. Liu Z, Xu W, Han J, Liu Q, Gao L, Wang X, et al. Quercetin induces apoptosis and enhances gemcitabine therapeutic efficacy against gemcitabine-resistant cancer cells. Anticancer Drugs (2020) 31:684-92. doi: 10.1097/CAD.0000000000000933

59. Lan C-Y, Chen S-Y, Kuo C-W, Lu C-C, Yen G-C. Quercetin facilitates cell death and chemosensitivity through RAGE/PI3K/AKT/mTOR axis in human pancreatic cancer cells. J Food Drug Anal (2019) 27:887-96. doi: 10.1016/j.jfda.2019.07.001

60. Sharmila G, Bhat FA, Arunkumar R, Elumalai P, Raja Singh P, Senthilkumar $\mathrm{K}$, et al. Chemopreventive effect of quercetin, a natural dietary flavonoid on prostate cancer in in vivo model. Clin Nutr (2014) 33:718-26. doi: 10.1016/ j.clnu.2013.08.011

61. Singh B, Mense SM, Bhat NK, Putty S, Guthiel WA, Remotti F, et al. Dietary quercetin exacerbates the development of estrogen-induced breast tumors in female ACI rats. Toxicol Appl Pharmacol (2010) 247:83-90. doi: 10.1016/ j.taap.2010.06.011

62. Khorshidi M, Moini A, Alipoor E, Rezvan N, Gorgani-Firuzjaee S, Yaseri M, et al. The effects of quercetin supplementation on metabolic and hormonal parameters as well as plasma concentration and gene expression of resistin in overweight or obese women with polycystic ovary syndrome: Quercetin supplementation and resistin level in PCOS. Phytother Res (2018) 32:2282-9. doi: $10.1002 /$ ptr.6166

63. Paller CJ, Rudek MA, Zhou XC, Wagner WD, Hudson TS, Anders N, et al. A phase I study of muscadine grape skin extract in men with biochemically recurrent prostate cancer: Safety, tolerability, and dose determination: Phase I Trial of MPX in BCR PCa. Prostate (2015) 75:1518-25. doi: 10.1002/pros.23024

64. Wilms LC, Boots AW, de Boer VCJ, Maas LM, Pachen DMFA, Gottschalk $\mathrm{RWH}$, et al. Impact of multiple genetic polymorphisms on effects of a 4-week blueberry juice intervention on ex vivo induced lymphocytic DNA damage in human volunteers. Carcinogenesis (2007) 28:1800-6. doi: 10.1093/carcin/bgm145

65. la Porte C, Voduc N, Zhang G, Seguin I, Tardiff D, Singhal N, et al. SteadyState Pharmacokinetics and Tolerability of Trans-Resveratrol $2000 \mathrm{mg}$ Twice Daily with Food, Quercetin and Alcohol (Ethanol) in Healthy Human Subjects. Clin Pharmacokinet (2010) 49:449-54. doi: 10.2165/ 11531820-000000000-00000

66. Rizzolio F. Nanomedicine in Cancer Pathology. Curr Med Chem (2018) 25:4190-1. doi: 10.2174/092986732534181026111151

67. Anchordoquy TJ, Barenholz Y, Boraschi D, Chorny M, Decuzzi P, Dobrovolskaia MA, et al. Mechanisms and Barriers in Cancer Nanomedicine: Addressing Challenges, Looking for Solutions. ACS Nano (2017) 11:12-8. doi: 10.1021/ acsnano.6b08244

68. Ahmed R, Amreddy N, Babu A, Munshi A, Ramesh R. Combinatorial Nanoparticle Delivery of siRNA and Antineoplastics for Lung Cancer
Treatment. In: L Dinesh Kumar, editor. RNA Interference and Cancer Therapy Methods in Molecular Biology. New York, NY: Springer New York (2019). p. 265-90. doi: 10.1007/978-1-4939-9220-1_20

69. Chen Z, Zhao P, Luo Z, Zheng M, Tian H, Gong P, et al. Cancer Cell Membrane-Biomimetic Nanoparticles for Homologous-Targeting DualModal Imaging and Photothermal Therapy. ACS Nano (2016) 10:1004957. doi: $10.1021 /$ acsnano.6b04695

70. Mangla B, Neupane YR, Singh A, Kohli K. Tamoxifen and Sulphoraphane for the breast cancer management: A synergistic nanomedicine approach. Med Hypotheses (2019) 132:109379. doi: 10.1016/j.mehy.2019.109379

71. Shroff RT, Javle MM, Xiao L, Kaseb AO, Varadhachary GR, Wolff RA, et al. Gemcitabine, Cisplatin, and nab-Paclitaxel for the Treatment of Advanced Biliary Tract Cancers: A Phase 2 Clinical Trial. JAMA Oncol (2019) 5:824. doi: 10.1001/jamaoncol.2019.0270

72. Jaiswal S, Mishra P. Co-delivery of curcumin and serratiopeptidase in HeLa and MCF-7 cells through nanoparticles show improved anti-cancer activity. Mater Sci Eng C (2018) 92:673-84. doi: 10.1016/j.msec.2018.07.025

73. Liu C-M, Chen G-B, Chen H-H, Zhang J-B, Li H-Z, Sheng M-X, et al. Cancer cell membrane-cloaked mesoporous silica nanoparticles with a $\mathrm{pH}$-sensitive gatekeeper for cancer treatment. Colloids Surf B Biointerfaces (2019) 175:477-86. doi: 10.1016/j.colsurfb.2018.12.038

74. Sun W, Du Y, Liang X, Yu C, Fang J, Lu W, et al. Synergistic triple-combination therapy with hyaluronic acid-shelled PPy/CPT nanoparticles results in tumor regression and prevents tumor recurrence and metastasis in $4 \mathrm{~T} 1$ breast cancer. Biomaterials (2019) 217:119264. doi: 10.1016/j.biomaterials.2019.119264

75. Xue X, Huang Y, Bo R, Jia B, Wu H, Yuan Y, et al. Trojan Horse nanotheranostics with dual transformability and multifunctionality for highly effective cancer treatment. Nat Commun (2018) 9:3653. doi: 10.1038/s41467-018-06093-5

76. Beg MS, Brenner AJ, Sachdev J, Borad M, Kang Y-K, Stoudemire J, et al. Phase I study of MRX34, a liposomal miR-34a mimic, administered twice weekly in patients with advanced solid tumors. Invest New Drugs (2017) 35:180-8. doi: 10.1007/s10637-016-0407-y

77. Macarulla T, Pazo-Cid R, Guillén-Ponce C, López R, Vera R, Reboredo M, et al. Phase I/II Trial to Evaluate the Efficacy and Safety of Nanoparticle Albumin-Bound Paclitaxel in Combination With Gemcitabine in Patients With Pancreatic Cancer and an ECOG Performance Status of 2. J Clin Oncol (2019) 37:230-8. doi: 10.1200/JCO.18.00089

78. Autio KA, Dreicer R, Anderson J, Garcia JA, Alva A, Hart LL, et al. Safety and Efficacy of BIND-014, a Docetaxel Nanoparticle Targeting ProstateSpecific Membrane Antigen for Patients With Metastatic CastrationResistant Prostate Cancer: A Phase 2 Clinical Trial. JAMA Oncol (2018) 4:1344. doi: 10.1001/jamaoncol.2018.2168

79. Schmid P, Adams S, Rugo HS, Schneeweiss A, Barrios CH, Iwata H, et al. Atezolizumab and Nab-Paclitaxel in Advanced Triple-Negative Breast Cancer. N Engl J Med (2018) 379:2108-21. doi: 10.1056/NEJMoa1809615

80. Murphy C, Muscat A, Ashley D, Mukaro V, West L, Liao Y, et al. Tailored NEOadjuvant epirubicin, cyclophosphamide and Nanoparticle AlbuminBound paclitaxel for breast cancer: The phase II NEONAB trial-Clinical outcomes and molecular determinants of response. PloS One (2019) 14: e0210891. doi: 10.1371/journal.pone.0210891

81. Merle P, Blanc J-F, Phelip J-M, Pelletier G, Bronowicki J-P, Touchefeu Y, et al. Doxorubicin-loaded nanoparticles for patients with advanced hepatocellular carcinoma after sorafenib treatment failure (RELIVE): a phase 3 randomised controlled trial. Lancet Gastroenterol Hepatol (2019) 4:454-65. doi: 10.1016/S2468-1253(19)30040-8

82. Serini S, Cassano R, Corsetto P, Rizzo A, Calviello G, Trombino S. Omega-3 PUFA Loaded in Resveratrol-Based Solid Lipid Nanoparticles: Physicochemical Properties and Antineoplastic Activities in Human Colorectal Cancer Cells In Vitro. Int J Mol Sci (2018) 19:586. doi: 10.3390/ijms19020586

83. Xin Y, Liu T, Yang C. Development of PLGA-lipid nanoparticles with covalently conjugated indocyanine green as a versatile nanoplatform for tumor-targeted imaging and drug delivery. Int J Nanomed (2016) 11:580721. doi: 10.2147/IJN.S119999

84. Geng T, Zhao X, Ma M, Zhu G, Yin L. Resveratrol-Loaded Albumin Nanoparticles with Prolonged Blood Circulation and Improved Biocompatibility for Highly Effective Targeted Pancreatic Tumor Therapy. Nanoscale Res Lett (2017) 12:437. doi: 10.1186/s11671-017-2206-6 
85. Yuan Y-G, Peng Q-L, Gurunathan S. Silver nanoparticles enhance the apoptotic potential of gemcitabine in human ovarian cancer cells: combination therapy for effective cancer treatment. Int J Nanomed (2017) 12:6487-502. doi: 10.2147/IJN.S135482

86. Fan C, Kong F, Shetti D, Zhang B, Yang Y, Wei K. Resveratrol loaded oxidized mesoporous carbon nanoparticles: A promising tool to treat triple negative breast cancer. Biochem Biophys Res Commun (2019) 519:378-84. doi: 10.1016/j.bbrc.2019.09.016

87. Peñalva R, Morales J, González-Navarro C, Larrañeta E, Quincoces G, Peñuelas I, et al. Increased Oral Bioavailability of Resveratrol by Its Encapsulation in Casein Nanoparticles. Int J Mol Sci (2018) 19:2816. doi: $10.3390 /$ ijms 19092816

88. Chaudhary Z, Subramaniam S, Khan GM, Abeer MM, Qu Z, Janjua T, et al. Encapsulation and Controlled Release of Resveratrol Within Functionalized Mesoporous Silica Nanoparticles for Prostate Cancer Therapy. Front Bioeng Biotechnol (2019) 7:225:225. doi: 10.3389/fbioe.2019.00225

89. Senthil Kumar C, Thangam R, Mary SA, Kannan PR, Arun G, Madhan B. Targeted delivery and apoptosis induction of trans-resveratrol-ferulic acid loaded chitosan coated folic acid conjugate solid lipid nanoparticles in colon cancer cells. Carbohydr Polym (2020) 231:115682. doi: 10.1016/ j.carbpol.2019.115682

90. Song Z, Shi Y, Han Q, Dai G. Endothelial growth factor receptor-targeted and reactive oxygen species-responsive lung cancer therapy by docetaxel and resveratrol encapsulated lipid-polymer hybrid nanoparticles. BioMed Pharmacother (2018) 105:18-26. doi: 10.1016/j.biopha.2018.05.095

91. Park SY, Chae SY, Park JO, Lee KJ, Park G. Gold-conjugated resveratrol nanoparticles attenuate the invasion and MMP-9 and COX-2 expression in breast cancer cells. Oncol Rep (2016) 35:3248-56. doi: 10.3892/or.2016.4716

92. Carletto B, Berton J, Ferreira TN, Dalmolin LF, Paludo KS, Mainardes RM, et al. Resveratrol-loaded nanocapsules inhibit murine melanoma tumor growth. Colloids Surf B Biointerfaces (2016) 144:65-72. doi: 10.1016/ j.colsurfb.2016.04.001

93. Lv Y, Hao L, Hu W, Ran Y, Bai Y, Zhang L. Novel multifunctional pHsensitive nanoparticles loaded into microbubbles as drug delivery vehicles for enhanced tumor targeting. Sci Rep (2016) 6:29321. doi: 10.1038/ srep29321

94. Gumireddy A, Christman R, Kumari D, Tiwari A, North EJ, Chauhan H. Preparation, Characterization, and In vitro Evaluation of Curcumin- and Resveratrol-Loaded Solid Lipid Nanoparticles. AAPS PharmSciTech (2019) 20:145. doi: 10.1208/s12249-019-1349-4

95. Kon E, Hazan-Halevy I, Rosenblum D, Cohen N, Chatterjee S, Veiga N, et al. Resveratrol Enhances mRNA and siRNA Lipid Nanoparticles Primary CLL Cell Transfection. Pharmaceutics (2020) 12:520. doi: 10.3390/ pharmaceutics 12060520

96. Elgizawy HA, Ali AA, Hussein MA. Resveratrol: Isolation, and Its Nanostructured, Inhibits Cell Proliferation, Induces Cell Apoptosis in Certain Human Cell Lines Carcinoma and Exerts Protective Effect Against Paraquat-Induced Hepatotoxicity. J Med Food (2020) 24:1:89-100. doi: 10.1089/jmf.2019.0286 jmf.2019.0286.

97. Lou M, Zhang L, Ji P, Feng F, Liu J, Yang C, et al. Quercetin nanoparticles induced autophagy and apoptosis through AKT/ERK/Caspase-3 signaling pathway in human neuroglioma cells: In vitro and in vivo. BioMed Pharmacother (2016) 84:1-9. doi: 10.1016/j.biopha.2016.08.055

98. Balakrishnan S, Mukherjee S, Das S, Bhat FA, Raja Singh P, Patra CR, et al. Gold nanoparticles-conjugated quercetin induces apoptosis via inhibition of EGFR/PI3K/Akt-mediated pathway in breast cancer cell lines (MCF-7 and MDA-MB-231). Cell Biochem Funct (2017) 35:217-31. doi: 10.1002/cbf.3266

99. Zhao H, Li L, Zhang J, Zheng C, Ding K, Xiao H, et al. C-C Chemokine Ligand 2 (CCL2) Recruits Macrophage-Membrane-Camouflaged Hollow Bismuth Selenide Nanoparticles To Facilitate Photothermal Sensitivity and Inhibit Lung Metastasis of Breast Cancer. ACS Appl Mater Interfaces (2018) 10:31124-35. doi: 10.1021/acsami.8b11645

100. Zhang J, Shen L, Li X, Song W, Liu Y, Huang L. Nanoformulated Codelivery of Quercetin and Alantolactone Promotes an Antitumor Response through Synergistic Immunogenic Cell Death for Microsatellite-Stable Colorectal Cancer. ACS Nano (2019) 13:12511-24. doi: 10.1021/acsnano.9b02875

101. Abbaszadeh S, Rashidipour M, Khosravi P, Shahryarhesami S, Ashrafi B, Kaviani $\mathrm{M}$, et al. Biocompatibility, Cytotoxicity, Antimicrobial and Epigenetic Effects of
Novel Chitosan-Based Quercetin Nanohydrogel in Human Cancer Cells. Int $J$ Nanomed (2020) 15:5963-75. doi: 10.2147/IJN.S263013

102. Bishayee K, Khuda-Bukhsh AR, Huh S-O. PLGA-Loaded GoldNanoparticles Precipitated with Quercetin Downregulate HDAC-Akt Activities Controlling Proliferation and Activate p53-ROS Crosstalk to Induce Apoptosis in Hepatocarcinoma Cells. Mol Cells (2015) 38:518-27. doi: 10.14348/molcells.2015.2339

103. Gupta A, Kaur CD, Saraf S, Saraf S. Formulation, characterization, and evaluation of ligand-conjugated biodegradable quercetin nanoparticles for active targeting. Artif Cells Nanomed Biotechnol (2015) 43:3:1-11. doi: 10.3109/21691401.2015.1008503

104. Zhu X, Zeng X, Zhang X, Cao W, Wang Y, Chen H, et al. The effects of quercetin-loaded PLGA-TPGS nanoparticles on ultraviolet B-induced skin damages in vivo. Nanomed Nanotechnol Biol Med (2016) 12:623-32. doi: 10.1016/j.nano.2015.10.016

105. Gismondi A, Reina G, Orlanducci S, Mizzoni F, Gay S, Terranova ML, et al. Nanodiamonds coupled with plant bioactive metabolites: A nanotech approach for cancer therapy. Biomaterials (2015) 38:22-35. doi: 10.1016/ j.biomaterials.2014.10.057

106. Luo C, Liu Y, Wang P, Song C, Wang K, Dai L, et al. The effect of quercetin nanoparticle on cervical cancer progression by inducing apoptosis, autophagy and anti-proliferation via JAK2 suppression. BioMed Pharmacother (2016) 82:595-605. doi: 10.1016/j.biopha.2016.05.029

107. Mashhadi Malekzadeh A, Ramazani A, Tabatabaei Rezaei SJ, Niknejad H. Design and system of multifunctional hyperbranched polymers coated magnetite nanoparticles for both targeting magnetic resonance imaging and cancer therapy. J Colloid Interface Sci (2017) 490:64-73. doi: 10.1016/ j.jcis.2016.11.014

108. Liu K, Chen W, Yang T, Wen B, Ding D, Keidar M, et al. Paclitaxel and quercetin nanoparticles co-loaded in microspheres to prolong retention time for pulmonary drug delivery. Int J Nanomed (2017) 12:8239-55. doi: 10.2147/IJN.S147028

109. Ren K-W, Li Y-H, Wu G, Ren J-Z, Lu H-B, Li Z-M, et al. Quercetin nanoparticles display antitumor activity via proliferation inhibition and apoptosis induction in liver cancer cells. Int J Oncol (2017) 50:1299-311. doi: 10.3892/ijo.2017.3886

110. Zhang Z, Xu S, Wang Y, Yu Y, Li F, Zhu H, et al. Near-infrared triggered codelivery of doxorubicin and quercetin by using gold nanocages with tetradecanol to maximize anti-tumor effects on MCF-7/ADR cells. $J$ Colloid Interface Sci (2018) 509:47-57. doi: 10.1016/j.jcis.2017.08.097

111. Nan W, Ding L, Chen H, Khan FU, Yu L, Sui X, et al. Topical Use of Quercetin-Loaded Chitosan Nanoparticles Against Ultraviolet B Radiation. Front Pharmacol (2018) 9:826:826. doi: 10.3389/fphar.2018.00826

112. Liu Q, Yang X, Sun J, Yu F, Zhang H, Gao J, et al. Size-Dependent Biological Effects of Quercetin Nanocrystals. Molecules (2019) 24:1438. doi: 10.3390/ molecules 24071438

113. Ma T, Liu Y, Wu Q, Luo L, Cui Y, Wang X, et al. Quercetin-Modified MetalOrganic Frameworks for Dual Sensitization of Radiotherapy in Tumor Tissues by Inhibiting the Carbonic Anhydrase IX. ACS Nano (2019) 13:4209-19. doi: 10.1021/acsnano.8b09221

114. Klein S, Luchs T, Leng A, Distel L, Neuhuber W, Hirsch A. Encapsulation of Hydrophobic Drugs in Shell-by-Shell Coated Nanoparticles for Radio-and Chemotherapy-An In Vitro Study. Bioengineering (2020) 7:126. doi: 10.3390/bioengineering7040126

115. Xiong Q, Wang Y, Wan J, Yuan P, Chen H, Zhang L. Facile preparation of hyaluronic acid-based quercetin nanoformulation for targeted tumor therapy. Int J Biol Macromol (2020) 147:937-45. doi: 10.1016/j.ijbiomac.2019.10.060

Conflict of Interest: The authors declare that the research was conducted in the absence of any commercial or financial relationships that could be construed as a potential conflict of interest.

Copyright $\odot 2021$ Saavedra-Leos, Jordan-Alejandre, López-Camarillo, Pozos-Guillen, Leyva-Porras and Silva-Cázares. This is an open-access article distributed under the terms of the Creative Commons Attribution License (CC BY). The use, distribution or reproduction in other forums is permitted, provided the original author(s) and the copyright owner(s) are credited and that the original publication in this journal is cited, in accordance with accepted academic practice. No use, distribution or reproduction is permitted which does not comply with these terms. 